\title{
Microchamber arrays for the identification of individual cells exposed to an X-ray microbeam
}

\author{
Takahiro Kuchimaru · Fuminobu Sato $\cdot$ Yusuke Aoi · \\ Tomohisa Fujita $\cdot$ Toshiji Ikeda $\cdot$ Kikuo Shimizu · \\ Yushi Kato · Toshiyuki Iida
}

Received: 28 February 2008/Accepted: 11 June 2008/Published online: 27 June 2008

(C) The Author(s) 2008

\begin{abstract}
To identify individual cells exposed to a X-ray microbeam in a cell population, we developed a biocompatible microchamber-array chip using UV lithography of photopolymer SU-8. The center-to-center distance between microchambers is $50 \mu \mathrm{m}$ including a wall of $15 \mu \mathrm{m}$ height. Using the microchamber-array chip, we performed tracking of individual exposed cells. Sample cells loaded in a microchamber array were selectively irradiated with the Xray microbeam under microscopic observation. All the irradiated cells were indexed by the array arrangement of the microchambers. For about $24 \mathrm{~h}$ of post-irradiation incubation, the irradiated cells were identified successfully by time-lapse observation. In addition, the induction of radiation effects was observed in identified cells using immunofluorescence.
\end{abstract}

\section{Introduction}

In this decade of radiobiology research, microbeam systems of ionizing radiation have been developed to perform

T. Kuchimaru $(\bowtie) \cdot$ F. Sato · Y. Aoi - T. Fujita · Y. Kato ·

T. Iida

Division of Electric, Electronic and Information Engineering,

Graduate School of Engineering, Osaka University, Suita,

Osaka 567-0871, Japan

e-mail: kuchimaru@nf.eie.eng.osaka-u.ac.jp

T. Ikeda

Institute of Scientific and Industrial Research, Osaka University,

Suita, Osaka, Japan

K. Shimizu

Radio Isotope Research Center, Osaka University, Suita,

Osaka, Japan single cell irradiation in cell populations [1,2]. Several researchers have revealed significant radiobiological effects with microbeams. One of them is the so-called "bystander effect" resulting from intercellular communication between cells exposed and unexposed to ionizing radiation [3]. Investigation of radiation responses in individual cells is necessary to understand the bystander effect. In normal culture system, however, the identification of individual cells is quite difficult in post-irradiation incubation because each cell moves randomly over the surface of the culture substrate [4].

Meanwhile, microfabricated devices for cell biology have increasingly been implemented in applied and basic biomedical research. This microtechnology provides researchers with new opportunities for the spatial and temporal control of cell growth environments [5-7]. For example, an on-chip observation system for isolated cells was proposed to study the fate of individual stem cells [8].

In this study, we developed a microchamber array to identify individual living cells for X-ray microbeam irradiation. A microchamber array was fabricated with UV lithography of photopolymer SU-8. Sample cells cultured in the microchamber array were irradiated selectively using an X-ray microbeam. In post-irradiation analysis, radiation effects of individual cells in a microchamber array were successfully observed with time-lapse microscopy observation and immunofluorescence technique.

\section{Materials and methods}

Fabrication of the microchamber-array chip

A microchamber array was fabricated with UV lithography of photopolymer SU-8. SU-8, which is solidified by the 
exposure to UV light, is widely used as photofabrication material for its mechanical characteristics, optical transparency, manufacturability and biocompatibility [9]. A schematic drawing of the fabrication process of a microchamber array is shown in Fig. 1. A glass coverslip of $18 \times 18 \mathrm{~mm}^{2}$ was spin-coated with SU-8 3050 photoresist (Microchem) at $2000 \mathrm{rpm}$ for $30 \mathrm{~s}$. The SU-8 layer was soft-baked for $10 \mathrm{~min}$ at $95^{\circ} \mathrm{C}$ to evaporate the solvent and solidify the photoresist and exposed to $365 \mathrm{~nm}$ UV light (40 $\mathrm{mW} \mathrm{\textrm {cm } ^ { - 2 }}$, SX-Ul 251HQ, USHIO) through a photomask for $30 \mathrm{~min}$. After baking for $6 \mathrm{~min}$ at a $95^{\circ} \mathrm{C}$, the SU8 layer was developed in SU-8 developer (Microchem) for $5 \mathrm{~min}$. The aluminum photomask was also fabricated with UV lithography. An aluminum evaporated (thickness: $500 \AA$ Á) glass coverslip was spin-coated with THMR-ip 5700HP photoresist (TOKYO OHKA KOGYO CO., LTD.). The photoresist was baked at $90^{\circ} \mathrm{C}$ for $90 \mathrm{~s}$ and scanned with a focused UV laser $(\lambda=405 \mathrm{~nm}$, CrystaLaser) to register a micro-pattern. After baking at $110^{\circ} \mathrm{C}$ for $90 \mathrm{~s}$, the photoresist was developed for $60 \mathrm{~s}$ in NMD-3 $2.38 \%$ (TOKYO OHKA KOGYO CO., LTD.). Lastly, the exposed aluminum layer was solved in $1 \% \mathrm{NaOH}$ solution for $60 \mathrm{~s}$ and residual photoresist was removed in $60 \%$ dimethyl slufoxide and $40 \% \mathrm{~N}$-methyl-2-pyrolidone solution. We also used purchased photomasks with a $70 \mu \mathrm{m}$ grid pattern (Edmund Optics) for the test fabrication.

Figure 2 shows photographs of a microchamber-array chip. The size of a microchamber is $50 \times 50 \mu \mathrm{m}^{2}$, and the depth was measured to be $15 \mu \mathrm{m}$ with laser microscope. To ensure biocompatibility, the microchamber-array chips were sterilized by autoclaving at $121^{\circ} \mathrm{C}$ for $15 \mathrm{~min}$ and then coated with $0.1 \%$ gelatin solution (ES-006-B, CHEMICON INTERNATIONAL) for $3 \mathrm{~h}$.

\section{Cell culture}

Rat pheochromocytoma PC12 cells were used as test cells for the investigation of radiation effects induced by the $\mathrm{X}$-ray microbeam. PC12 is widely used as in vitro neuron model cell [10]. Also, it is reported that the inflammatory cytokine interleukin-6 (IL-6) is produced under ionizing radiation in these cells [11]. IL-6 is known to induce various effects on neuronal cells [12-14], which might serve as signaling factors in ionizing radiation-induced intercellular communication. PC12 was obtained from Dr. Kushibiki (Osaka University, Osaka, Japan). Cells were cultured with Dulbecco's modified Eagle's medium (DMEM) containing 10\% fetal bovine serum and 5\% horse serum in a $5 \% \mathrm{CO}_{2}$ and $95 \%$ air humidified atmosphere at $37^{\circ} \mathrm{C}$. The cells were subcultured once a week with a split ratio of 1:6.

\section{Single cell irradiation}

A schematic drawing of the X-ray microbeam irradiation with the microchamber-array chip is shown in Fig. 3. The tabletop X-ray microbeam system based on a commercial $\mathrm{X}$-ray microscope was described previously [15]. Briefly, $\mathrm{X}$-rays generated by a micro-focus $\mathrm{X}$-ray tube (voltage: $\sim 50 \mathrm{kV}$, current: $\sim 1 \mathrm{~mA}$ ) are collimated to $12 \mu \mathrm{m}$ diameter [FWHM] with a glass capillary [16]. Maximum dose rate was estimated to be $0.3 \mathrm{~Gy} \mathrm{~s}^{-1}$ with photon counting measurement and energy deposit simulation. Single cells can be irradiated manually by a control of the sample stage under microscopic observation. Regular objectives of $20 \times$ and $40 \times$ magnification are interchangeable to observe the sample cells. After irradiation, the cells on the microchamber-array chip were incubated according to the cell culture protocol.

\section{Immunofluorescence stainings}

In post-irradiation analysis, immunofluorescence stainings were performed to detect the production of IL- 6 and $\gamma$ $\mathrm{H} 2 \mathrm{AX}[17,18]$. As mentioned before, the autocrine induction of IL-6 in PC12 under ionizing radiation was reported. IL-6 is known to induce various effects on neuronal cells. We assumed that IL-6 from irradiated cell may interact with unirradiated cells in the bystander effect. It is known that $\gamma$-H2AX formation is rapidly induced at sites of
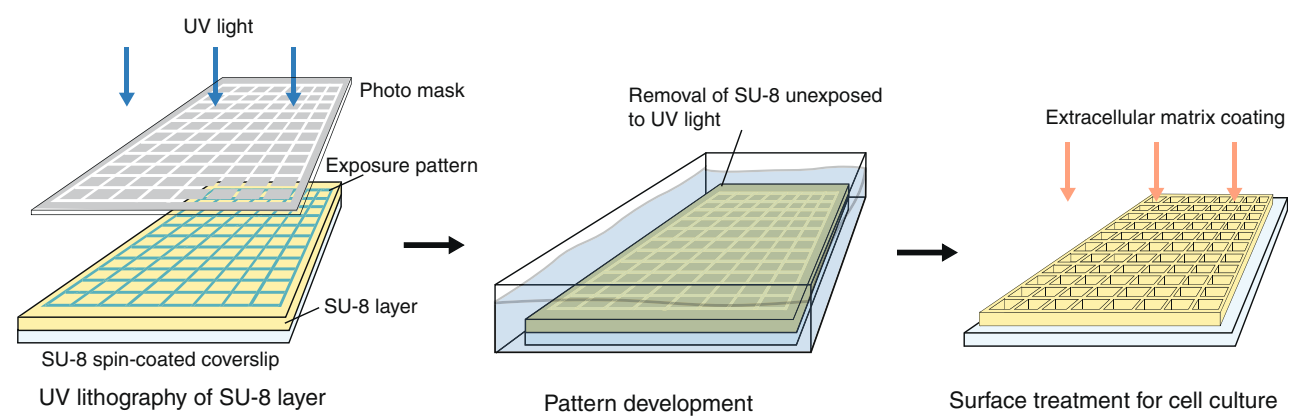

Pattern development

Surface treatment for cell culture

Fig. 1 Schematic drawing of the fabrication process of a microchamber array 
Fig. 2 a Photograph of a microchamber-array chip in a $35 \mathrm{~mm}$ culture dish. b Microscopic photograph of a microchamber array. One of the corners is distinct to allow orientation in microbeam irradiation. Scale bars are $100 \mu \mathrm{m}$
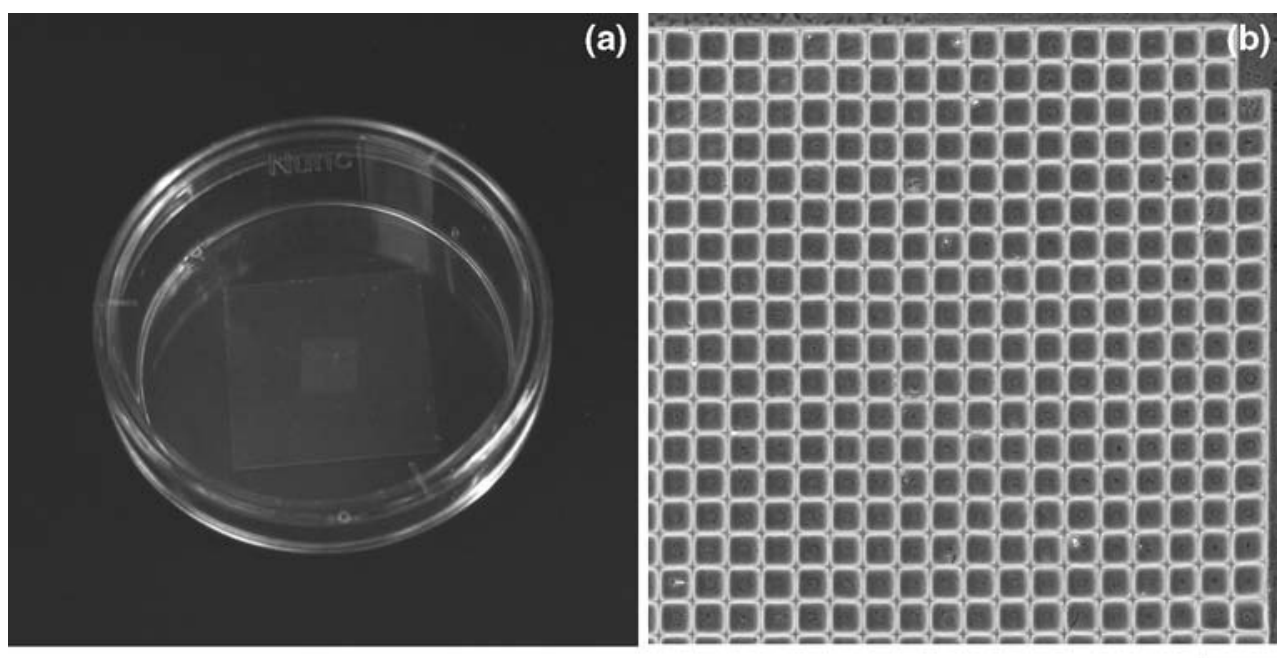

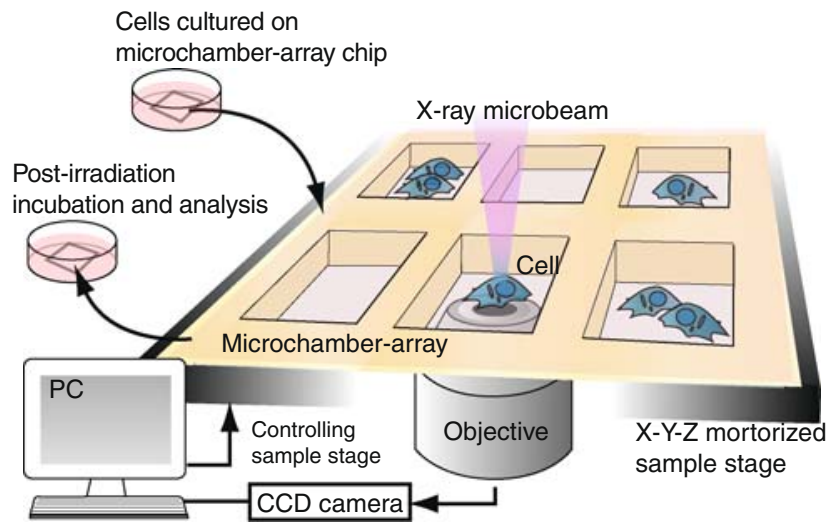

Fig. 3 Schematic drawing of X-ray microbeam irradiation with a microchamber-array chip. X-ray microbeam is incident on the upper surface of a cell. In microbeam irradiation, a microchamber-array chip was picked up from a culture dish and coated with a kapton film of $7 \mu \mathrm{m}$ thickness to prevent air contamination. The sample chip is set on a sterilized sample stage

DNA double-strand breaks (DSBs), and therefore it is widely used to visualize the DSBs [19]. After post-irradiation incubation, cells were fixed in $4 \%$ paraformaldehyde in phosphate-buffered saline (PBS) for $10 \mathrm{~min}$ on ice, washed in PBS and permeabilized in TNBS solution (PBS supplemented with $0.1 \%$ Triton $\mathrm{X}-100$ and $5 \%$ bovine serum albumine (BSA)) for $30 \mathrm{~min}$. Cells were washed and incubated with diluted 1:200 rat IL-6 primary antibody (SANTA CRUZ BIOTECH.) in PBS with $2 \%$ BSA overnight at $4^{\circ} \mathrm{C}$ or $1: 500 \quad \gamma$-H2AX primary antibody (Molecular Probes) in PBS with 2\% BSA for 90 min. After washing in TNBS, fluorescent second antibody Alexa Fluor $^{\circledR} 488$ (Molecular Probes), diluted to 1:250, was added for $60 \mathrm{~min}$ and the sample was then washed several times in TNBS. Hoechst 33342 was used for nuclear staining $\left(0.5 \mu \mathrm{g} \mathrm{mL}^{-1}, 20 \mathrm{~min}\right)$. All samples were observed using a standard fluorescent microscope (IX71,
Olympus) with mercury lamp excitation. To allow direct comparisons, all of the fluorescent images were obtained using the same microscopy parameters. The fluorescence intensity of $\gamma-\mathrm{H} 2 \mathrm{AX}$ foci was measured with Adobe Photoshop 7.0 and ImageJ $1.38 \times$ softwares. For quantitive analysis, the mean grey values of foci per nucleus were obtained from $\gamma-\mathrm{H} 2 \mathrm{AX}$ foci images extracted with a color filter. For each sample, cell measurement was performed until at least 20 cells were registered. Three independent experiments were performed for each data point.

\section{Results and discussion}

PC12 cells were seeded onto the microchamber-array chip in a $35 \mathrm{~mm}$ culture dish. Figure 4 shows the distribution of cell number in one microchamber at a cell seeding density of $5.0 \times 10^{4}, 7.5 \times 10^{4}$ or $1.0 \times 10^{5}$ cells $\mathrm{mL}^{-1}$, respectively. The number of chambers containing a single cell was not proportional to the cell seeding density, because at

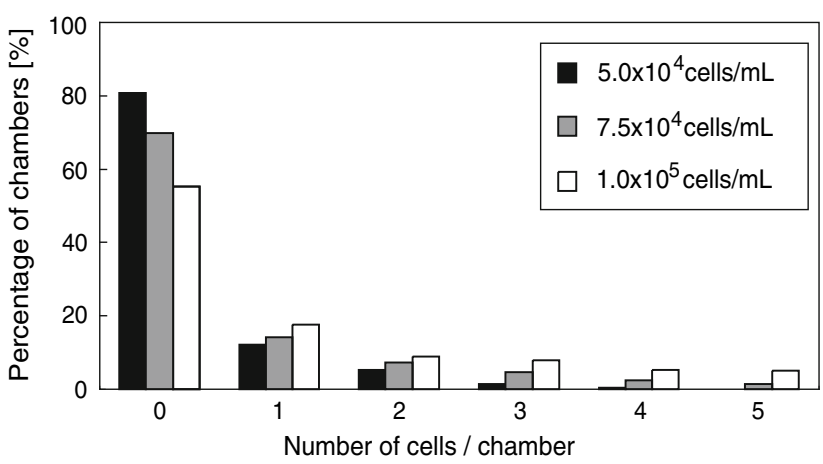

Fig. 4 The distribution of cell number per microchamber at different cell seeding densities. Cells were counted $24 \mathrm{~h}$ after cell seeding. The data were mean values from independent three experiments 

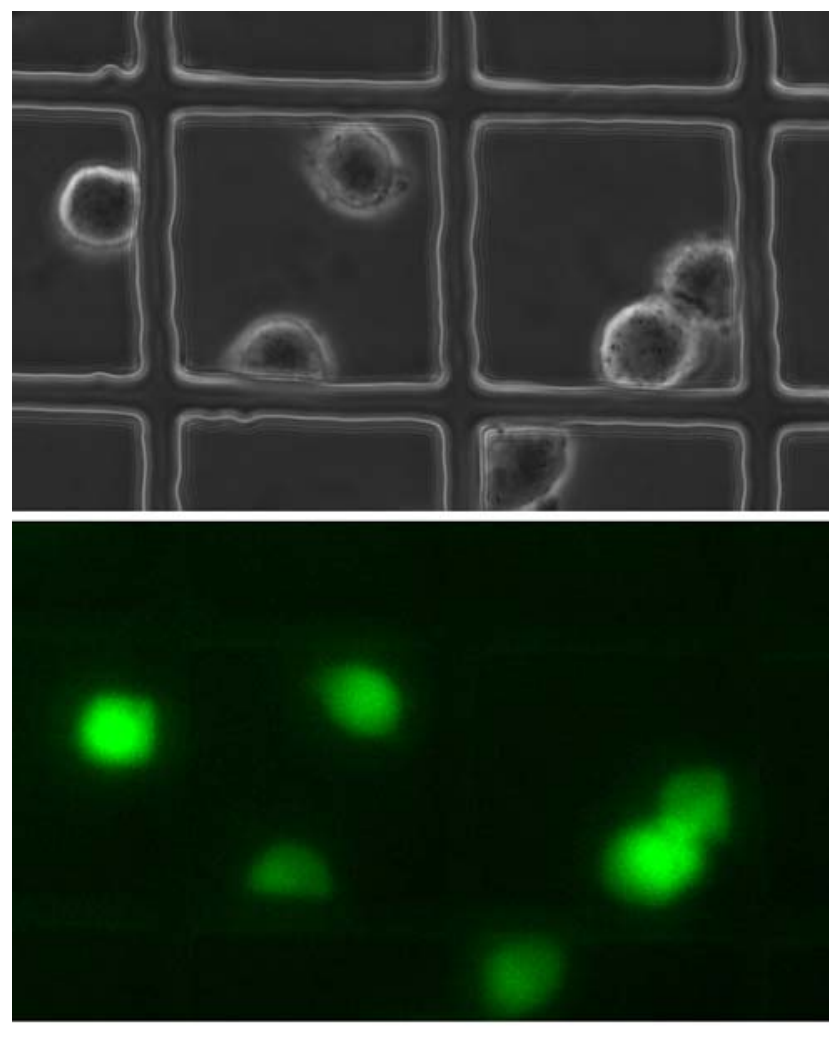

Fig. 5 Photographs of BCECF-loaded PC12 cells in microchambers. A $3-\mu \mathrm{M} \mathrm{mL}^{-1}$ solution of BCECF-AM ester in DMSO was added for $20 \mathrm{~min}$ and the fluorescence was observed at an excitation wavelength of $488 \mathrm{~nm}$. Fluorescence indicates cell viability. Scale bar is $50 \mu \mathrm{m}$ high density, the cells readily attached to each other before dwelling in the microchamber.

At $24 \mathrm{~h}$ after cell seeding, the viability of the PC12 cells in the microchambers was tested with the viability and $\mathrm{pH}$ indicator BCECF-AM reagent (Molecular Probes) [20]. $\mathrm{BCECF}-\mathrm{AM}$ is a fluorescein derivative that is cleaved to a fluorescent product by non-specific esterase present in living cells. In Fig. 5, the strong fluorescence spots indicate that the respective cells in the microchambers are alive.

Cells were seeded at a density of $5.0 \times 10^{4}$ cells $\mathrm{mL}^{-1}$ onto a microchamber-array chip $24 \mathrm{~h}$ before X-ray microbeam irradiation. During irradiation, all the irradiated cells were indexed via the array arrangement of the microchambers. During post-irradiation incubation, tracking of irradiated cells was performed with time-lapse microscopic observation. Figure 6 shows time-lapse photographs of individual PC12 cells in microchambers. After incubation, the induction of radiation effects was checked in irradiated cells with fluorescence analyses. At $24 \mathrm{~h}$ after irradiation, IL-6 production was clearly observed in cells exposed to 6 Gy of X-ray microbeam (Fig. 6).

Cell death induced by X-ray microbeam irradiation was estimated by propidium iodide test (10 $\mu \mathrm{M}$ for $10 \mathrm{~min})$ and counting missing cells due to detaching from a substrate. Approximately $60 \%$ of the cells irradiated with 6 Gy did not survive at $24 \mathrm{~h}$ after irradiation. Next, we investigated the time-course of DNA damage in PC12 cells. Irradiated cells were observed in microchambers at 1, 3, 9 and $24 \mathrm{~h}$ after X-ray microbeam irradiation. Figure 7 shows the
Fig. 6 Time-lapse photographs of a PC12 cell (a) exposed to 6 Gy of X-ray microirradiation and (b) of an unirradiated cells. Photographs were taken every $3 \mathrm{~h}$ for $24 \mathrm{~h}$ of post-irradiation incubation. In both cases, after $24 \mathrm{~h}$ incubation the cell sample was fixed and IL-6 was detected by immuofluorescence (last fields in the rows). The exposure time of fluorescence microscopy was fixed to $1.5 \mathrm{~s}$ in both cases. A strong fluorescence, indicating IL-6 expression, is seen in the fluorescent image of (a), but not in (b). Scale bar is $50 \mu \mathrm{m}$ (a)
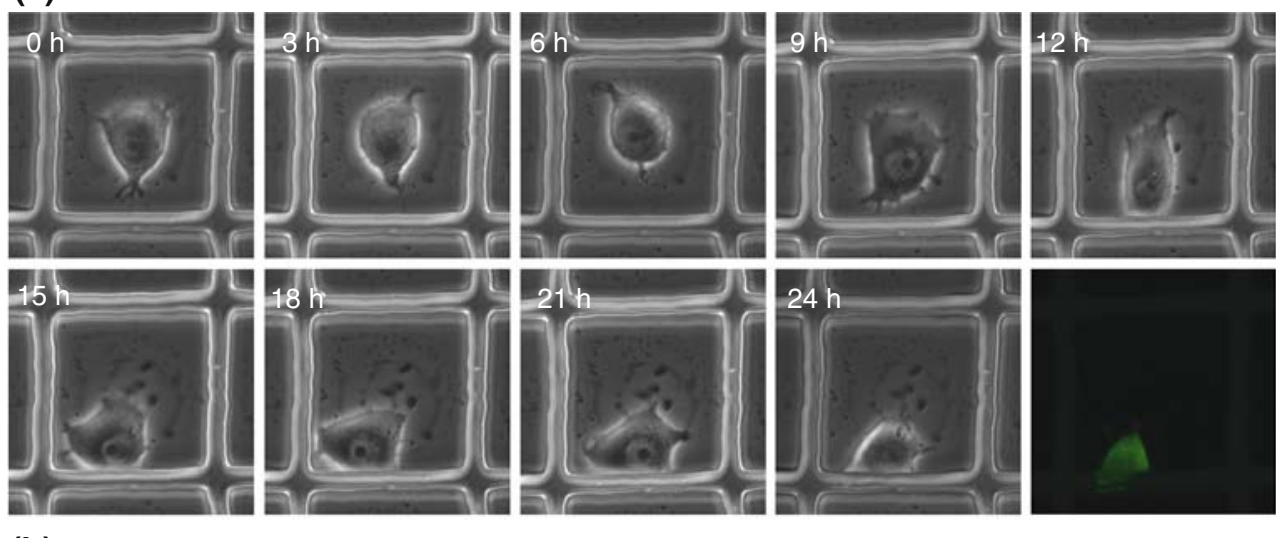

(b)
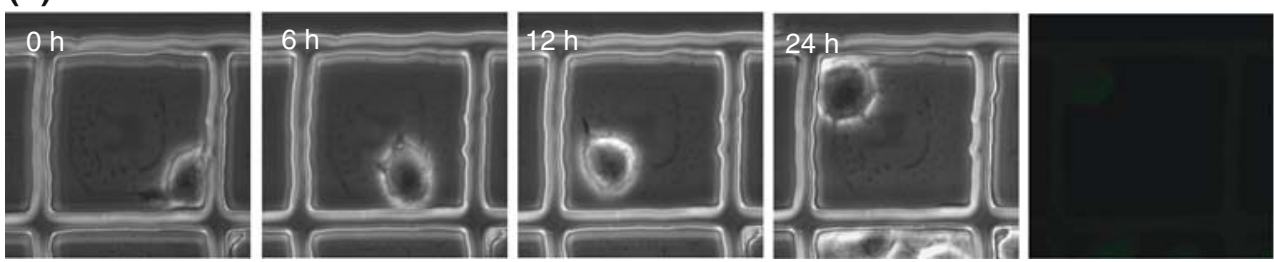
(a)

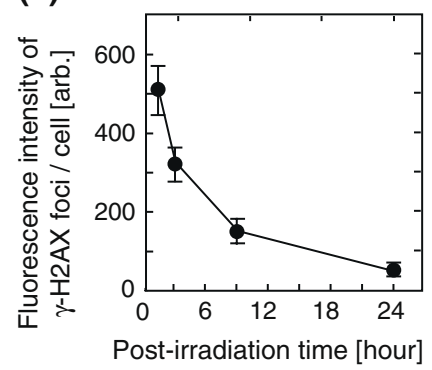

Fig. 7 a Time-course changes of fluorescence intensity of $\gamma$-H2AX foci after exposure to $6 \mathrm{~Gy}$ of $\mathrm{X}$-ray microbeam. After a postirradiation incubation of $1,3,9$ and $24 \mathrm{~h}$, the cells were fixed for fluorescence staining. b Images of $\gamma-\mathrm{H} 2 \mathrm{AX}$ foci in $\mathrm{PC} 12$ cell nuclei

time-course of fluorescent intensity of $\gamma$-H2AX foci. Most of the $\gamma$-H2AX signal was eliminated on surviving PC12 cell at $24 \mathrm{~h}$ after irradiation, reflecting DNA DSB repair [21].

In summary, we developed a biocompatible microchamber array with UV lithography of photopolymer SU-8. The microchamber array was found to be useful to analyze radiation effects induced by an $\mathrm{X}$-ray microbeam in individual cells. The microchamber array may be applied in a similar manner to particle microbeam irradiation experiments. Microfabrication of SU-8 on a thin substrate to deliver particle beams from lower surface of a cell was described [22]. We believe that observation techniques based on microchamber arrays might become standard platforms to study single cell irradiation.

Acknowledgments The authors appreciate Dr. Kushibiki (Osaka University), Dr. Matsumoto (Tokyo Institute of Technology), Dr. Kodama and Dr. Shiraishi (University of Osaka Prefecture) for helpful advises and discussion of biological experiments. This work was supported by Grant-in-Aid for Scientific Research from the Ministry of Education, Culture, Sports, Science and Technology, Japan and Grant-in-Aid for JSPS Fellows.

Open Access This article is distributed under the terms of the Creative Commons Attribution Noncommercial License which permits any noncommercial use, distribution, and reproduction in any medium, provided the original author(s) and source are credited.

\section{References}

1. Randers-Pehrson G, Geard CR, Johnson CD, Elliston CD, Brenner DJ (2001) The Columbia University single-ion microbeam. Radiat Res 156:210-214

2. Folkard M, Schettino G, Vojnovic B, Gilchrist S, Michette AG, Pfauntsch SJ, Prise KM, Michael BD (2001) A focused ultrasoft X-ray microbeam for targeting cells individually with submicrometer accuracy. Radiat Res 156:796-804

3. Nagasawa H, Little JB (1992) Induction of sister chromatid exchange by extremely low dose of a particles. Cancer Res 52:6394-6396 induced by 6 Gy irradiation of X-ray microbeam. Observation images were acquired with a water immersion objective of $\times 60$ magnification (NA: 1.25). Error bars are \pm 1 SD. Scale bar is $10 \mu \mathrm{m}$

4. Lee J, Ishihara A, Jacobson K (1993) How do cells move along surface? Trends Cell Biol 11:366-370

5. El-Ali J, Sorger PK, Jensen F (2006) Cell on ships. Nature 442:403-411

6. Moriguchi H, Wakamoto Y, Sugio Y, Takahashi K, Inoue I, Yasuda K (2002) An agar-microchamber cell-cultivation system: flexible change of microchamer shapes during cultivation by photo-thermal etching. Lab Chip 2:125-130

7. Gross GP, Katalov EP, Scherer A, Weiner LP (2007) Application of microfluidics for neuronal studies. J Neurol Sci 252:135-143

8. Chin VI, Taupin P, Sanga S, Scheel J, Gage FH, Bhatia SN (2004) Microfabricated platform for studying stem cell fates. Biotech Bioeng 88:399-415

9. Voslerician G, Shive MS, Shawgo RS, Recum H, Anderson JM, Langer R (2003) Biocompatibility and biofouling of MEMS drug delivery devices. Biomat 24:1959-1967

10. Green LA, Tischler AS (1976) Establishment of a noradrenergic clonal line of rat adrenal pheochromocytoma cells which respond to nerve growth factor. Proc Natl Acad Sci USA 73:2424-2428

11. Abeyama K, Kawano K, Nakajima T, Takasaki I, Kitajima I, Maruyama I (1995) Interleukin 6 mediated differentiation and rescue of cell redox in PC12 cells exposed to ionizing radiation. FEBS Lett 364:298-300

12. Sparkman NL, Buchanan JB, Heyen RRJ, Chen J, Beverly LJ, Johonson WR (2006) Interkeukin-6 facilitates lipopolysaccharide-induced disruption in working memory and expression of other proinflammatory cytokines in hippocampal neuronal cell layers. J Neurosci 26:10709-10716

13. Sallmann S, Juttler E, Printz S, Petersen N, Knopf U, Weiser T, Schwaninger M (2000) Induction of interleukin-6 by depolarization of neurons. J Neurosci 20:8637-8642

14. Sarder M, Abe K, Saito H, Nishiyama N (1996) Comparative effect of IL-2 and IL-6 on morphology of cultured hippocampal neurons from fetal rat brain. Brain Res 715:9-16

15. Kuchimaru T, Sato F, Higashino Y, Shimizu K, Kato Y, Iida T (2006) Microdosimetric characteristics of Micro X-ray beam for single cell irradiation. IEEE Trans Nucl Sci 53:1363-1366

16. Sato F, Kuchimaru T, Ikeda T, Shimizu K, Kato Y, Iida T (2008) $\mathrm{X}$-ray microbeam measurement with radiophotoluminescent glass plate for single cell irradiation. Radiat Meas (in press)

17. Tabata C, Kubo H, Tabata R, Wada M, Sakuma K, Ichikawa M, Fujita S, Mio T, Mishima M (2006) All-trans retinoic acid modulates radiation-induced proliferation of lung fibroblasts via IL-6/IL6R system. Am J Physiol Lung Cell Mol Physiol 290:597-606

18. Hu B, Wu L, Han W, Ahang L, Chen S, Xu A, Hei TK, Yu Z (2006) The time and spatial effects of bystander response in mammalian cells induced by low dose radiation. Carcinogenesis $27: 245-251$ 
19. Macphail SH, Banath JP, Yu TY, Chu EHM, Lambur H, Olive PL (2003) Expression of phosphorylated histone H2AX in cultured cell lines following exposure to X-rays. Int J Radiat Biol 79:351358

20. Chu CR, Monosov AZ, Amiel D (1995) In situ assessment of cell viability within biodegradable polylactic acid polymer matrices. Bioma 16:1381-1384

21. Nazarov IB, Smirnova AN, Krutilina RI, Stveltova MP, Solovjeva LV, Nikifrov AA, Oei S-L, Zalenskaya IA, Yau PM,
Bradbury EM, Tomilin NV (2003) Dephosphorylation of histone $\gamma$-H2AX during repair of DNA double-strand breaks in mammalian cells and its inhibitation by calyculin A. Radiat Res 160:309-317

22. Arteaga-Marrero N, Auzelyte V, Olsson MG, Pallon J (2007) A SU-8 dish for cell irradiation. Nucl Instr and Meth B 263:523528 